\title{
Developing a Smart Home Solution Based on Personalized Intelligent Interior Units to Promote Activity and Customized Healthcare for Aging Society
}

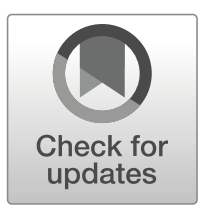

\author{
Rongbo Hu ${ }^{1}$ (D) Thomas Linner ${ }^{1}$ - Julian Trummer $^{1} \cdot$ Jörg Güttler $^{1}$ • \\ Amir Kabouteh ${ }^{1} \cdot$ Katharina Langosch ${ }^{1} \cdot$ Thomas Bock $^{1}$
}

Received: 5 August 2019 / Accepted: 30 January 2020 / Published online: 5 March 2020

(C) The Author(s) 2020

\begin{abstract}
The world's population is aging at an unprecedented pace. Aging society is not only a severe crisis in the developed world, but also a rigorous challenge in emerging economies. Many age-related diseases are fostered by the lack of physical, cognitive, and social activities. Increasing the activity level has many benefits for the elderly and can improve their independence. Based on the analysis of the state-of-the-art and shortcomings of the current smart home solutions, the EU-funded research project REACH aims to develop a service system that will turn clinical and care environments into personalized modular sensing, prevention, and intervention systems that encourage the elderly to become healthy through various activities. To achieve that goal, the research team developed a series of smart furniture ( $\left.\mathrm{PI}^{2} \mathrm{Us}\right)$ that materialize the research concepts and functionality seamlessly into the various environments. Specifically, the development process and the functionality testing results of the $\mathrm{PI}^{2} \mathrm{Us}$ are reported in detail. In addition, a simulated smart home solution concept (TRACK) integrating key assistive technologies developed is proposed to create a comprehensive interior living and care environment for elderly users. Due to its modularity and flexibility, the partial or entire solution can be easily adapted and rapidly deployed in different use case settings in Europe, which allows the project consortium to execute different testing activities. In the next phase, the research team will focus on enhancing the usability and performance of the prototypes in order to eventually push them to the market. In conclusion, this research provides an innovative smart home solution for the industry to mitigate the impact of aging society.
\end{abstract}

Keywords Activity · Assistive technology · Personalized intelligent interior units · Sensing technology $\cdot$ Smart furniture $\cdot$ Smart home

Rongbo Hu

rongbo.hu@br2.ar.tum.de

1 Technical University of Munich, Munich, Germany 


\section{Background}

The world's population is aging at an unforeseen rate. Aging society is a crisis that is experienced all around the globe, including developed countries such as Germany and Japan, and emerging economies such as China. According to the 2017 Revision of the World Population Prospects, the percentage of global older population (aged 60 or over) increased from 9\% in 1994 to $13 \%$ in 2017 and is expected to reach $21 \%$ by 2050 (United Nations 2017). This phenomenon puts tremendous pressure on the global health care system. For instance, the health expenditure in the European Union is expected to rise by $350 \%$ by 2050 compared to an economic growth of only $180 \%$ in the same timeframe (Espinoza 2011). The Directorate General for Economic and Financial Affairs reported that the provision of long-term care (LTC), in particular, will pose an increasing challenge to the sustainability of public finances in the European Union, due to an aging population (Lipszyc et al. 2012). Evidently, many age-related diseases are fostered by a lack of physical, cognitive, and social activities. Increasing the level of activity has many benefits for the elderly and can improve their level of independence (McPhee et al. 2016). Apparently, there are both an urgent need and substantial market potential to develop solutions to tackle these challenges.

In the following sections, this paper presents an innovative smart home solution based on smart furniture to encourage activity and customized healthcare in the context of aging society. Based on a brief overview of the state-of-the-art research, the research question is stated, and the methods used in this development are reported. Furthermore, the results of smart furniture development as well as the concept for deployment are presented.

\section{Related Work and Research Aim}

In recent years, due to the pressure from social challenges such as ageing societies, limited resources, and a continuously increasing demand for productivity and efficiency, the topics of smart furniture and smart homes are becoming more and more popular.

It has been demonstrated that smart furniture to a limited extent can integrate sensory and intervention functionality (Linner et al. 2015) as well as elements of the building technology. A particular focus in that context was given to the development of smart chairs (Erdt et al. 2012), smart bathroom furniture (Manoel et al. 2017), smart kitchens (Yan et al. 2007; Beetz et al. 2008), smart home workspaces (Linner et al. 2016) and smart beds (Spillman et al. 2004; Van der Loos et al. 2003). A significant shortcoming of the aforementioned furniture schemes is that the majority are stand-alone devices that are not integrated into a larger framework (i.e., they are not connected to other components and do not form part of a bigger analytical scheme that makes use of the large quantity of information that can possibly be produced through such processes) or are incapable of monitoring the entire area where they are positioned. A further weakness is the lack of modularity and the limited amount of functionality the systems provide.

There are several intelligent sensing solutions proposed, such as the Aware Home (Kidd et al. 1999) and the RoboticRoom (Sato et al. 2004). All of them are 
ambitious proposals of implementation of smart environments (i.e. buildings or rooms that are equipped with sensing functions for sensing of a large amount of data, intervention modules and robotic functionality). All aforementioned examples use sensor networks for intelligent robots (Murakami et al. 2008) and achieved positive results. These examples are aspiring, but at the same time are extremely specialized and, in particular, lack the capacity to integrate such environments into a regular home or home care setting due to their high cost and the need for fundamental changes to the environmental architecture. Also, due to the lack of considering modularity, the installation process of these systems is complex and time consuming. Furthermore, given that the systems are not highly specialized and unified, they operate only based on their own capabilities without complementing each other in functionality and often monitor similar aspects twice or more, leading to high redundancy and cost.

The transformation of buildings into smart homes (Intille et al. 2006; Hsu 2012), assistive environments for senior citizens (Wichert and Mand 2017), or robotic environments (Sugano and Shirai 2006; Williams and Nayak 1996; Kurazume et al. 2017; Pyo et al. 2015) are currently in the focus of the research and development of both academia and industry. However, many attempts have been made to embed distributed sensory and motivation functions into the built environment to support the monitoring and care for healthier and more independent elderly people's living (Intille 2002; Intille 2004; Pyo et al. 2014; Sakamura 1996; Sato et al. 2004). In addition, despite the opportunities these technologies provide, their real-world deployment oftentimes requires an intrusion into the physical building and to a large extent is hindered by their complexity, time and cost associated with equipping buildings with such functionality.

Therefore, this paper aims to address the abovementioned shortcomings by presenting a methodological approach to develop modular service solution that will turn clinical and care environments into personalized sensing, prevention, and intervention systems, encouraging the elderly to become healthy through being both physically and mentally active.

\section{Methods}

One of the major goals of this research is to overcome key shortcomings of abovementioned smart environments by installing functionality into easily deployable and mass customizable furniture elements. These furniture elements can be prefabricated and preconfigured in workshops or factories and can be deployed easily in contrast to conventional smart home technology. During the development and implementation of these technologies, modularity will be one of the main considered aspects, in order to achieve easy integration to the environment and minimize modifications of the environment. Furthermore, the outcomes of this research will allow European industries, including small- and medium-sized enterprises, to capitalize on the European high-tech know-hows, making Europe a world leader in prevention technologies, services, and underlying ICT healthcare platforms, and meanwhile tackle the ultimate crisis of rising healthcare expenditures (Hu et al. 2019). The key methods of this research are presented as follows. 


\section{Touchpoints and Engine Concept}

In the project, an experimental, interdisciplinary sensing-monitoring-intervention system is developed that can be placed unobtrusively in various care settings and living environments of elderly citizens. The system aims to 1) use a variety of sensors to detect specific vital signs, behavioral patterns, and health status; 2) predict future health status, risks or events; and 3) anticipatorily provide a series of customized health products and services that support and promote physical activities. As a result, the Healthy Life Years (HLY) of the elderly would increase, and their time spent in LTC facilities would be reduced (Bock 2017). Therefore, the research team developed the "Touchpoints and Engine" concept as a comprehensive solution of the system architecture for the research project. It further guides the detailed structural relation between the subsystems of the project. With the "Touchpoints and Engine" concept, the product-servicesystem architecture of REACH is divided into six manageable research and development clusters: four Touchpoint clusters (in other words, work groups each focusing on a specific topic within the project, including Touchpoint 1: Personal Mobility Device, Touchpoint 2: Active Environment, Touchpoint 3: Socializing \& Nutritional Monitoring/Intervention, and Touchpoint 4: Gaming \& Training System) that represent tangible connections between users (e.g., seniors, caregivers, physicians, etc.) and the REACH system; one "Engine" cluster, which is a cloud-based digital platform serving as the brain of the project; and one "Interface" cluster, which comprises a set of means that allow the Touchpoints and other products and services to interact with the Engine. Each cluster is associated with a dedicated and independent development team coming from the project consortium members (see Fig. 1) (Linner et al. 2017).

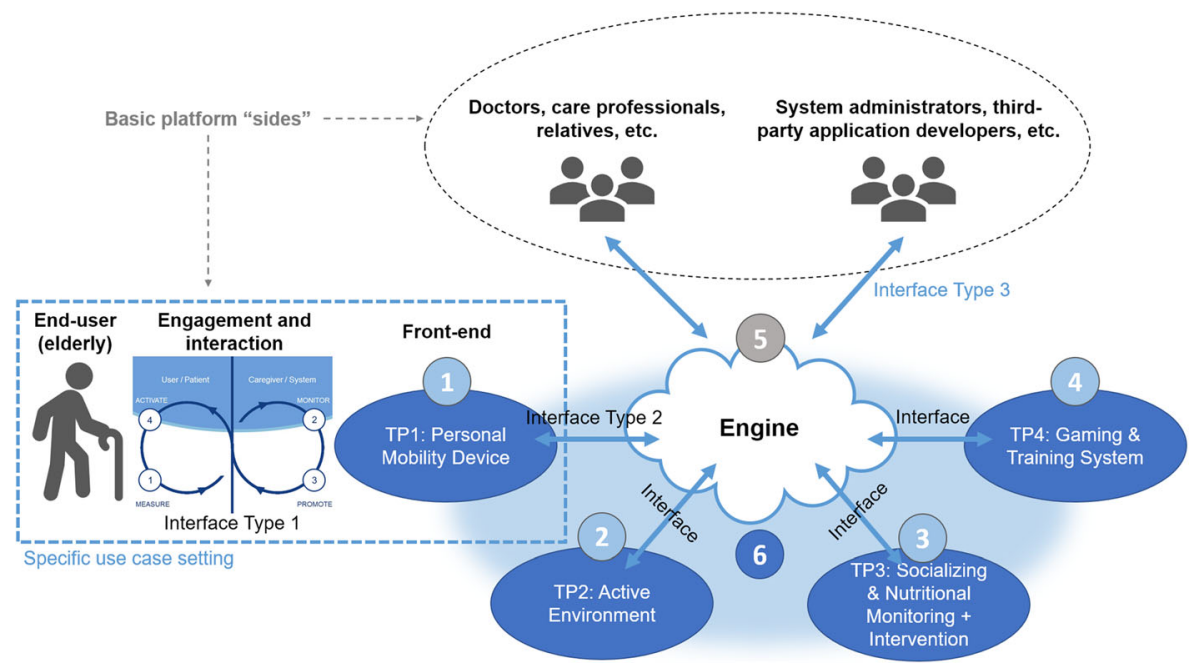

Fig. 1 "Touchpoints and Engine" concept in REACH. 


\section{Determining Design Requirements}

In order to have a successful development process, it is important to conduct requirements analysis before the design process starts. A description of the target user including the user environment and an analysis of the entities associated with the user were performed. Various methods were applied to describe and analyze these key components of the REACH system, including describing use cases, defining personas, creating experience maps, and analyzing stakeholders (Schäpers et al. 2017). Subsequently, the major hypotheses of four Touchpoints were concluded based on these analyses. For example, in Touchpoint 2, the hypothesis is formulated as follows: the REACH system based on smart furniture elements with sensing systems enables the patients to reduce the duration of their hospitalization, reduce decline after discharge, reduce risk of readmission, and be able to perform their activities of daily living (ADLs) with reduced support from professional caregivers.

\section{Iterative Development of the Smart Furniture}

The Personalized Intelligent Interior Unit $\left(\mathrm{PI}^{2} \mathrm{U}\right)$ is a special type of smart furniture that seamlessly integrates the required concepts and functionality into the different use case settings. This paper focuses on a series of $\mathrm{PI}^{2} \mathrm{Us}$ developed by the project team in Touchpoint 2 (i.e., the "Active Environment" work group of the project). The relevant $\mathrm{PI}^{2} \mathrm{Us}$ include $\mathrm{PI}^{2} \mathrm{U}-\mathrm{SilverArc}, \mathrm{PI}^{2} \mathrm{U}-$ MiniArc, $\mathrm{PI}^{2} \mathrm{U}-\mathrm{SilverBed}$, and $\mathrm{PI}^{2} \mathrm{U}-\mathrm{iStander}$ Design iteration is a common practice in product design and is proved to be efficient and suitable for developing prototypes according previous research (Ren et al. 2016). Therefore, the development process of the $\mathrm{PI}^{2} \mathrm{Us}$ follows iterative design principles on both hardware and software levels, which allows the project team to optimize the products through prototyping, testing, analyzing, and refining (Cockburn 2008). As illustrated in Fig. 2, the project team completed the development and functionality testing of first or second prototypes of relevant $\mathrm{PI}^{2} \mathrm{Us}$. Future versions of the $\mathrm{PI}^{2} \mathrm{Us}$ are currently being developed and will be tested with elderly users regarding usability and performance.

\section{Results}

In the following sections, the designs and prototype iterations of $\mathrm{PI}^{2} \mathrm{Us}$ in Touchpoint 2 are reported and the results of the functionality testing activities based on the $\mathrm{PI}^{2} \mathrm{Us}$ are presented in detail.

\section{PI²U-SilverArc}

The $\mathrm{PI}^{2} \mathrm{U}-\mathrm{SilverArc}$ was developed for the use in a large kitchen or dining space (e.g., a community kitchen). It offers an interactive projection area in the kitchen, where recipes and games can be displayed. It also has a foldaway projection area where a training program can be displayed (see Fig. 3). The round shapes, wood material, and bright colors give the $\mathrm{PI}^{2} \mathrm{U}-\mathrm{SilverArc}$ a warm and inviting presence. 


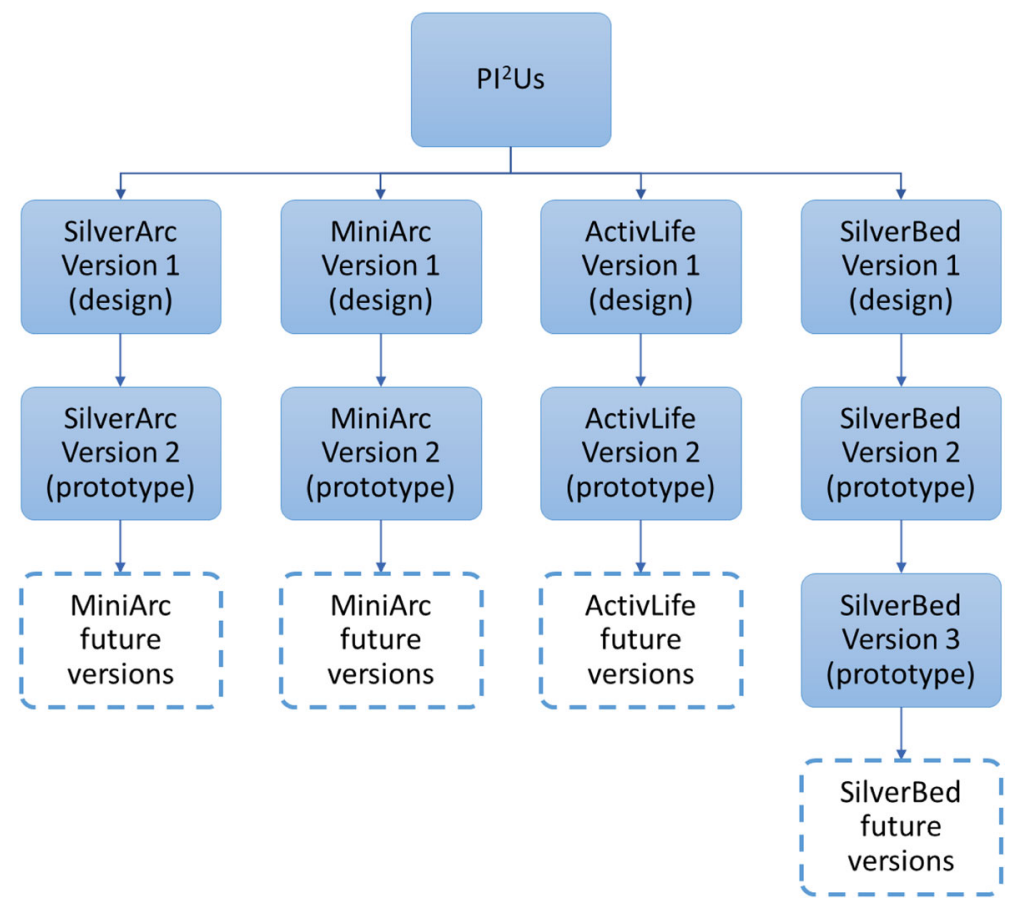

Fig. 2 Iterative design process of the $\mathrm{PI}^{2} \mathrm{Us}$

The preliminary design of the $\mathrm{PI}^{2} \mathrm{U}-\mathrm{SilverArc}$ was not suitable to be converted directly into a prototype. For example, the material of the prototype and the final

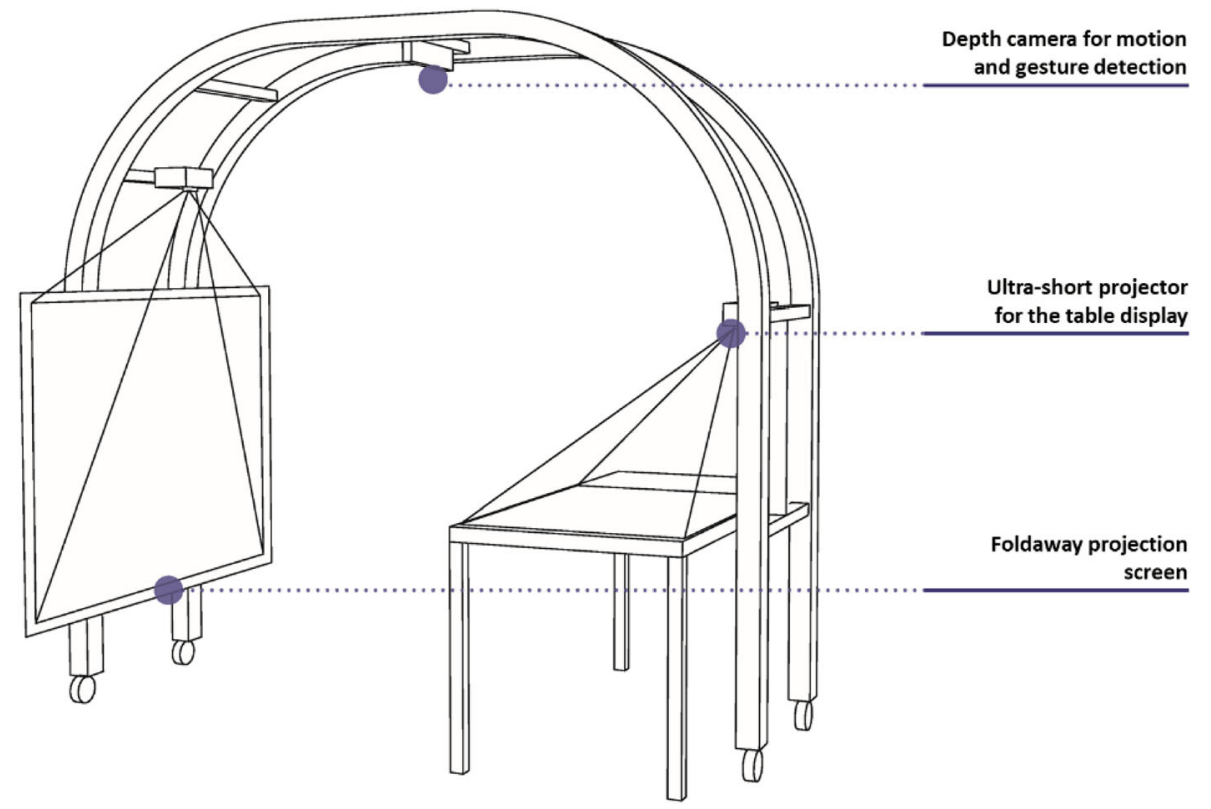

Fig. 3 Preliminary design of the $\mathrm{PI}^{2} \mathrm{U}-$ SilverArc 
product differ substantially. After evaluation, it was decided that MayTec's modular aluminum profile system is suitable for building the prototypes. MayTec $\mathrm{GmbH}$ offers a wide range of modular profiles, accessories, and different connection possibilities (http://www.maytec.com.de/). Using the aluminum profile scheme, simple modifications can be created after the first test. In conjunction, in order to reduce costs, the curves in the prototypes were omitted because they mainly serve an aesthetic function and are not necessary for the functionality testing. However, it is important to manufacture future iterations of the prototypes using the shape and material proposed in the preliminary design, and test them with the elderly people regarding the usability and performance of the $\mathrm{PI}^{2} \mathrm{Us}$.

Figure 4 shows in detail how the technical equipment is integrated into the prototype. An ultra-short projector is fixed above the projection screen. It was deliberately decided against a mounting under the projection area, since the dust load for the projection lens would increase. Depth cameras are attached to a sliding system for easy positioning adjustment.

In order to make the system easier for the elderly to use, the project team developed an intuitive and user-friendly graphical user interface (GUI) that can be applied to both $\mathrm{PI}^{2} \mathrm{U}-$ SilverArc and $\mathrm{PI}^{2} \mathrm{U}$-MiniArc. The major functions of the GUI include, but are not limited to time, calendar, weather, appointment reminder, email, game center, and photo gallery (see Fig. 5). The size of the GUI can be adjusted according to various use case scenarios, including tables, projection screens and walls. The users can easily use their fingertips as the mouse to operate the program.

\section{PI2U-MiniArc}

The PI ${ }^{2} \mathrm{U}-M i n i A r c$ can be considered as a flexible and smaller variant of the $\mathrm{PI}^{2} \mathrm{U}-$ SilverArc, which is designed to assist in the training and moving of the elderly who are hospitalized or live in smaller apartments. An ultrashort projector can

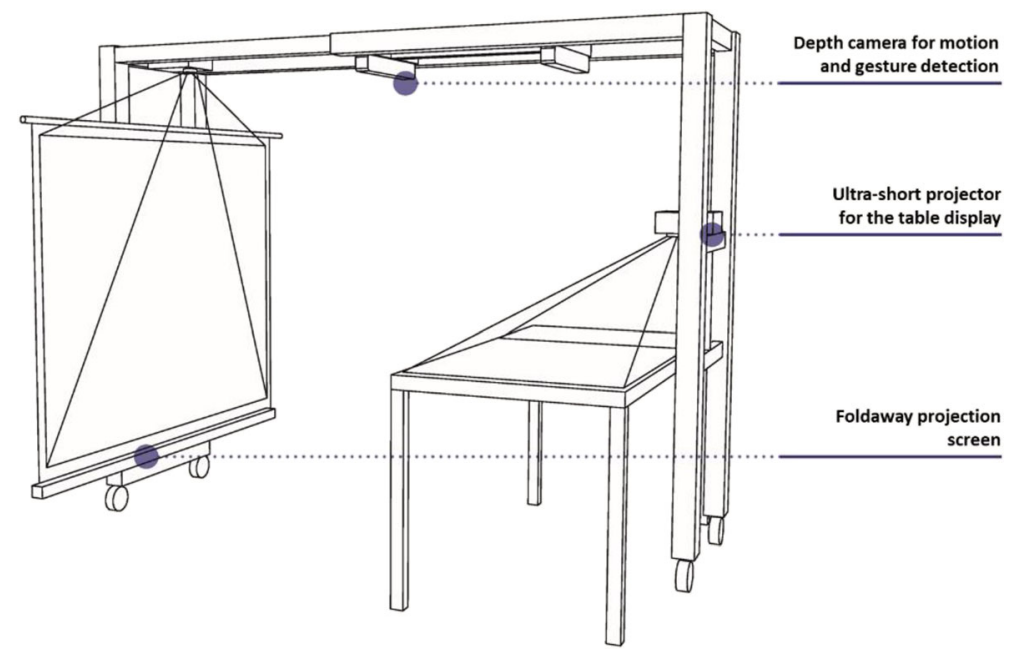

Fig. 4 Prototypical version of the $\mathrm{PI}^{2} \mathrm{U}-$ SilverArc 


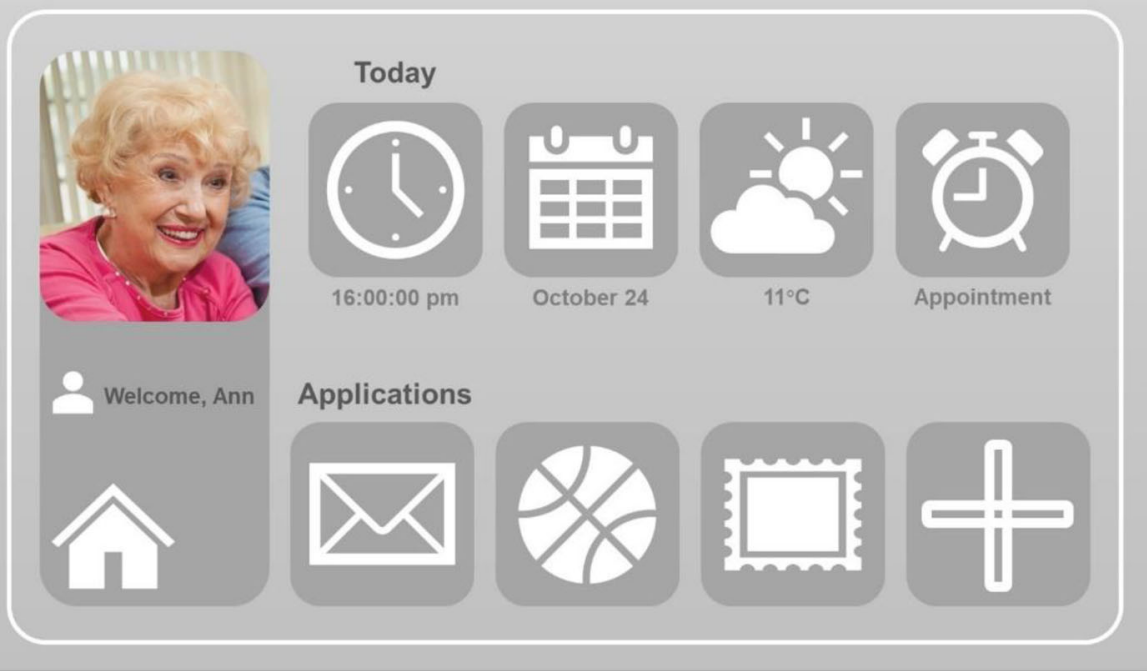

Fig. 5 Schematic diagram of the GUI's home screen

project the user interface on its foldaway table or on a separate table as needed. In addition, a motion-sensing camera (Microsoft Kinect) is integrated to detect the user's gestures, enabling the interactive gaming function. There is another projector on top of the device that can project supplementary information onto a wall. This prototype is fitted with wheels and is thus mobile. Figures 6 and 7 respectively demonstrate the preliminary design and the final prototypical version of the $\mathrm{PI}^{2} \mathrm{U}-$ MiniArc.

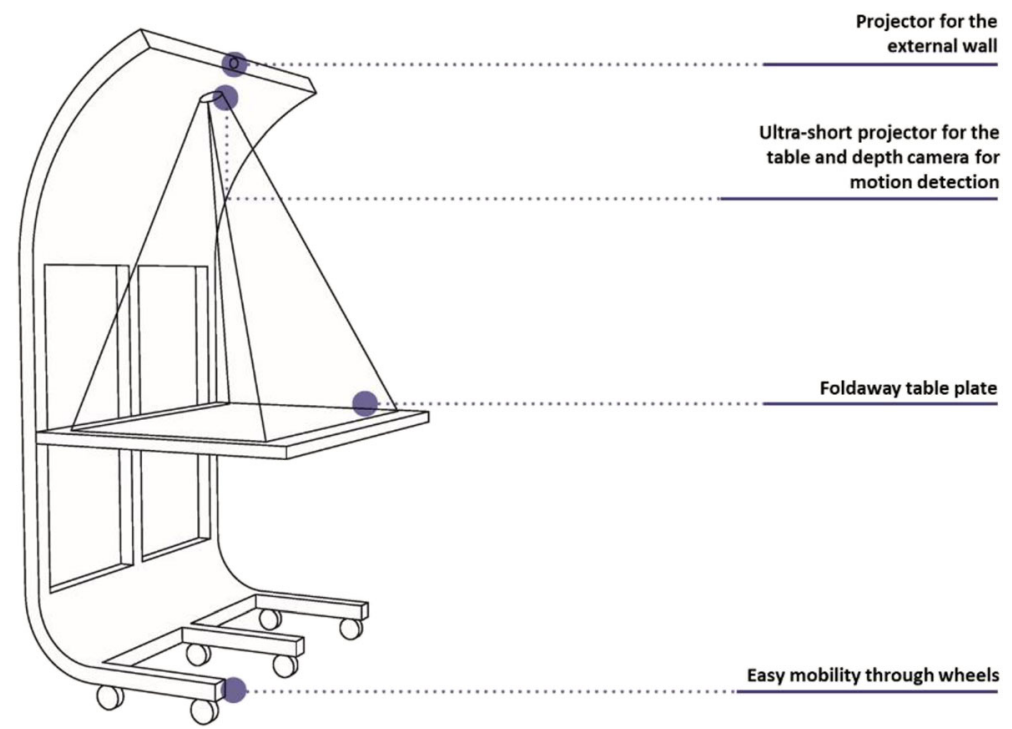

Fig. 6 Preliminary design of the $\mathrm{PI}^{2} \mathrm{U}-\mathrm{Mini}$ Arc 


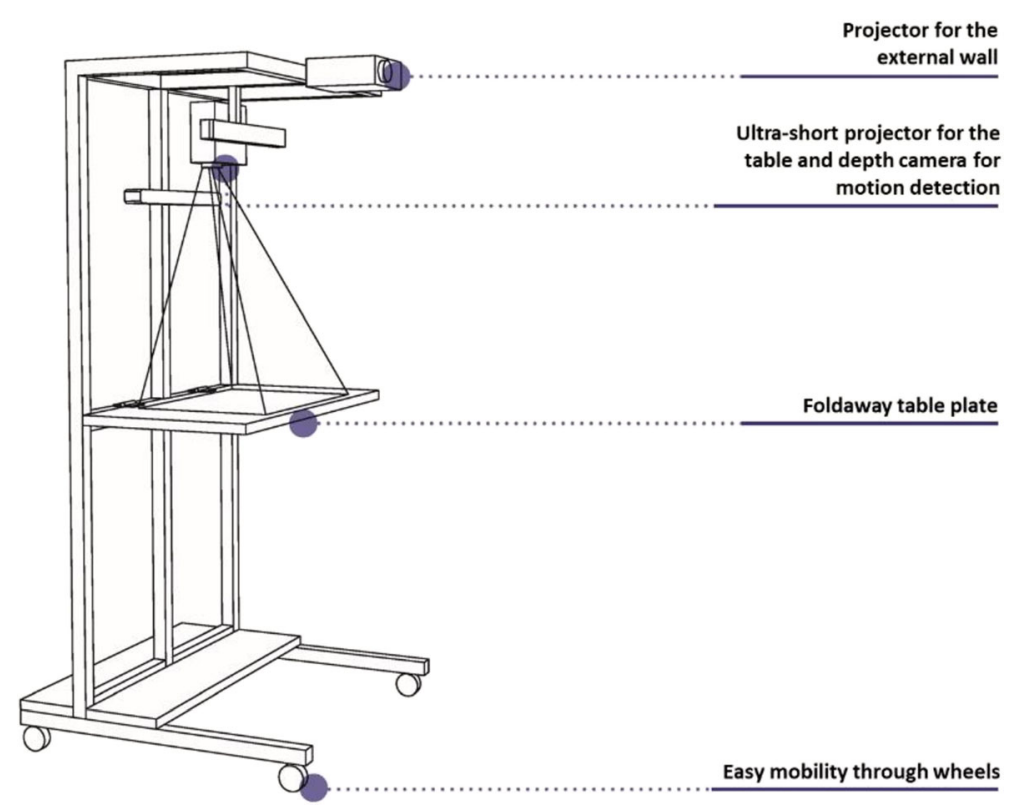

Fig. 7 Prototypical version of the $\mathrm{PI}^{2} \mathrm{U}-$ MiniArc

\section{PI2U-SilverBed}

As shown in Fig. 8, the first design of the $\mathrm{PI}^{2} \mathrm{U}-\mathrm{S}$ ilverBed resembles a normal bed for private use. As a special feature, an arc-shaped frame covers the entire length of the bed, which allows for an easy integration of sensors and technologies such as a thermal camera for breath detection and a projector for the bed. The height of the bed can be adjusted. On the one hand, this feature makes it possible for the caregivers to work at a height that is comfortable for their stature. On the other hand, the lowest height of the bed facilitates the transfer of the patient from the bed to other functional units such as a wheelchair. The bed can be set to both a sitting and a vertical position. The sitting position allows the bed to support the patient and the nurse in many tasks such as eating, while the vertical position is especially apt for patients in an Intensive Care Unit (ICU), who must perform the transfer from lying to vertical position. The passive standing that is enabled by a standing frame aims to improve respiratory function and cardiovascular fitness, increase the levels of consciousness, functional independence, and psychological well-being, and reduce the risk for delirium and the adverse effects of immobility (Stiller and Phillips 2003).

In order to adapt the bed system to each patient's needs, a modular docking system was integrated into the design. Modules providing additional functions such as a toilet, physical training, transfer, and mobility can dock at different positions in the frame of the bed and are symmetric and self-guided. For example, with the Leg-curl Training Module (see Fig. 8), the patient can rest on their abdomen and use their legs to move the weight up and down. Training muscles is imperative to the performance of daily tasks.

To validate the concept of the $\mathrm{PI}^{2} \mathrm{U}-\mathrm{SilverBed}$, a prototype was planned and built using the aforementioned aluminum profile system. Figure 9 shows the final design of 


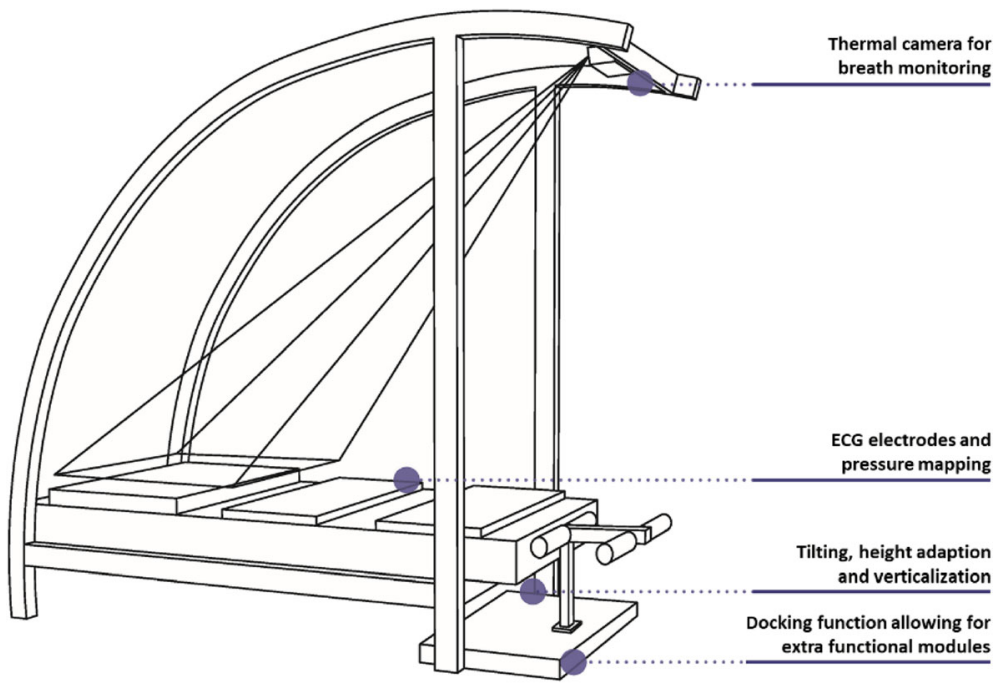

Fig. 8 Preliminary design of the $\mathrm{PI}^{2} \mathrm{U}-$ SilverBed

the $\mathrm{PI}^{2} \mathrm{U}-\mathrm{SilverBed}$ prototype that was manufactured. After testing the prototype, the project team discovered several drawbacks in this version despite fulfilling the majority of assumptions concerning functionality during the laboratory testing. For example, the load capacity of the position changing mechanism is not satisfactory compared to a professional hospital bed. Furthermore, the heavy usage of aluminum material makes it difficult to appeal to seniors especially when it is used in resting space.

Therefore, the project team revised the design with a different approach: to incorporate a Sara Combilizer with a carpentry-based Activation Cockpit around it. The Sara Combilizer is a combination of a chair and a tilt table developed by REACH partner Arjo, which can allow even immobile patients to be moved to a sitting, standing, or supine position in a comfortable and safe manner (McWilliams et al. 2017). The

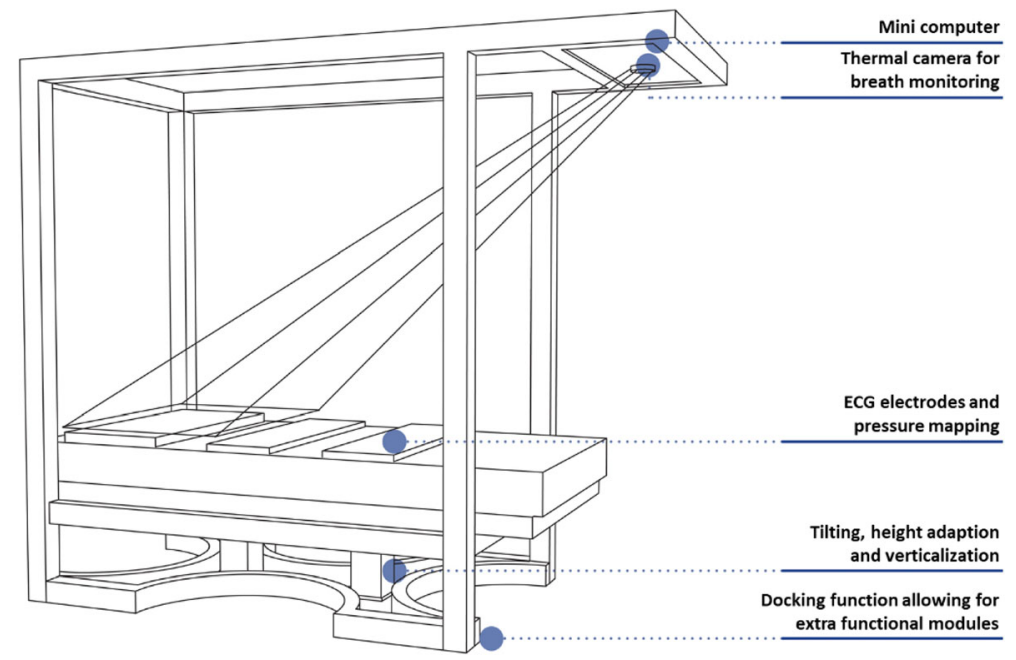

Fig. 9 First prototypical version of the $\mathrm{PI}^{2} \mathrm{U}-$ SilverBed 
activation cockpit is another key element of this version of the $\mathrm{PI}^{2} \mathrm{U}-\mathrm{SilverBed}$. It expands the functionality of Sara Combilizer and provides a surrounding where the elderly with reduced mobility can not only sleep in, but also spend their day in an active way. With this new version of $\mathrm{PI}^{2} \mathrm{U}-$ SilverBed, physical exercise is offered in combination with entertainment, motivating its users to become more active. More importantly, health functions can be also integrated such as vital signs monitoring (will be described in detail later) and direct access to drinking water. Additionally, docking function to other rehabilitation devices can be included as well, allowing users to transfer safely between the Sara Combilizer and PI²U-iStander. The system is highly modularized so that specific add-ons and plug-ins can be tailored for each individual and included in the Activation Cockpit in endless possible combinations. Being highly adaptable, the Activation Cockpit is suitable for both home and hospital use (see Fig. 10).

\section{$\mathrm{PI}^{2} \mathrm{U}-$ iStander and ActivLife Gaming Platform}

The $\mathrm{PI}^{2} \mathrm{U}-\mathrm{iStander}$ is developed by project partner Alreh Medical to activate the physical and mental activity of people of old age whose daily activity level has decreased. It is used to prevent elderly people from falling and provides effective support for cognitive processes through the combination of physical and cognitive exercises (Kozak et al. 2017). Due to its flexibility and comparable size to a small treadmill, the system can be easily deployed in spaces such as living rooms and bedrooms (see Fig. 11). The device is equipped with a mechanism to assist the elderly user to stand up and to perform motor exercises of the ankles, knees, and hip joints. A special corset and a seat ensure safety during the exercises that strengthen the back and abdominal muscles by lifting the legs. It also allows the user to maintain a safe, upright standing position and perform balance exercises as

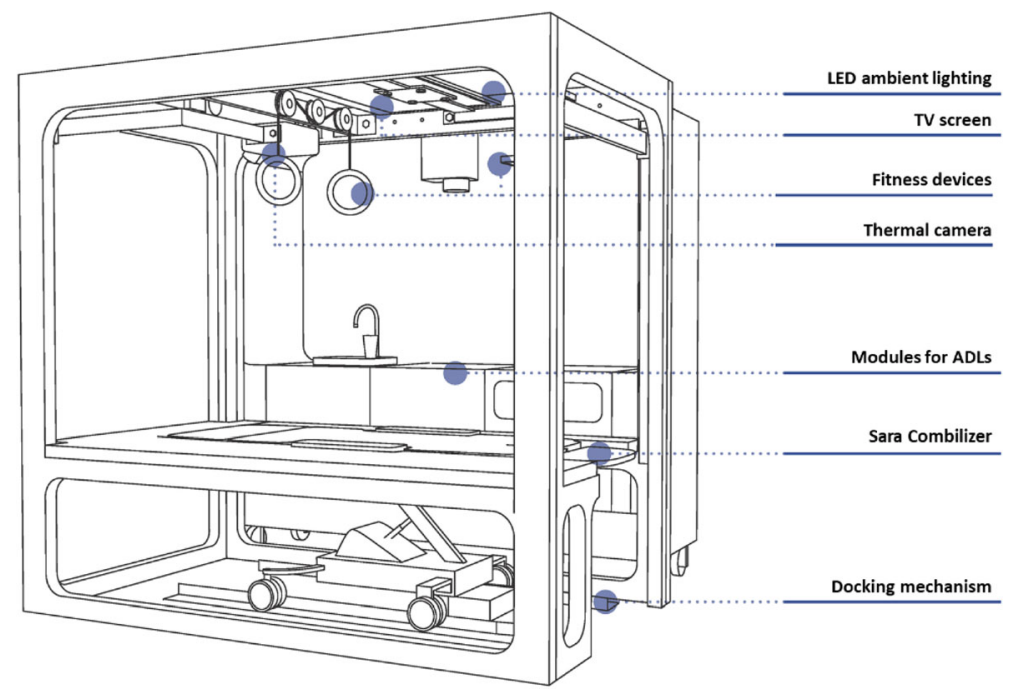

Fig. 10 Second prototypical version of the $\mathrm{PI}^{2} \mathrm{U}-$ SilverBed comprising the Activation Cockpit and Sara Combilizer 
well as exercises where the upper body parts are activated using the ActiveLife Gaming Platform (see Fig. 12).

\section{Major Sensing, Monitoring, and Analysis Activities Using the $\mathrm{PI}^{2} \mathrm{Us}$}

As mentioned in the previous sections, a series of $\mathrm{PI}^{2} \mathrm{Us}$ are developed in Touchpoint 2. The $\mathrm{PI}^{2} \mathrm{U}$ prototypes are manufactured, currently deployed, and tested for main sensing, monitoring, and analysis activities in the laboratory (see Fig. 13). The functionality testing results of these activities are presented as follows, which clearly demonstrate how various sensors and functions can be integrated into the $\mathrm{PI}^{2} \mathrm{Us}$ due to their modularity and customizability.

The electrocardiogram (ECG) sensors, which are embedded in the PI²U-SilverBed, can provide the medical staff with data regarding the patient's heart activity during the sleeping period. Additionally, this aspect can support the early detection aspect of the research. Figure 14 presents the sensor integration on the $\mathrm{PI}^{2} \mathrm{U}-\mathrm{SilverBed}$ which produces usable ECG measurement signals in the second image (Fig. 14 middle). In order to implement such sensors, flexible plastic material was used to improve patient comfort and measurement (Fig. 14 right). The ECG implementation uses two electrodes to produce more accurate ECG signals (Pehr et al. 2019).

An important issue when considering an immobile patient's care is the prevention and management of pressure ulcers or decubitus. In order to implement the early detection and prevention aspects of the research in the $\mathrm{PI}^{2} \mathrm{U}-\mathrm{SilverBed}$, it was decided to integrate a pressure-sensing mattress. This mattress monitors the peak pressure points of a person lying on the bed. Using this data, the Engine can monitor peak pressure points and inform the care personnel for repositioning the patient before they develop decubitus. This sensor provides other functions as well such as breath
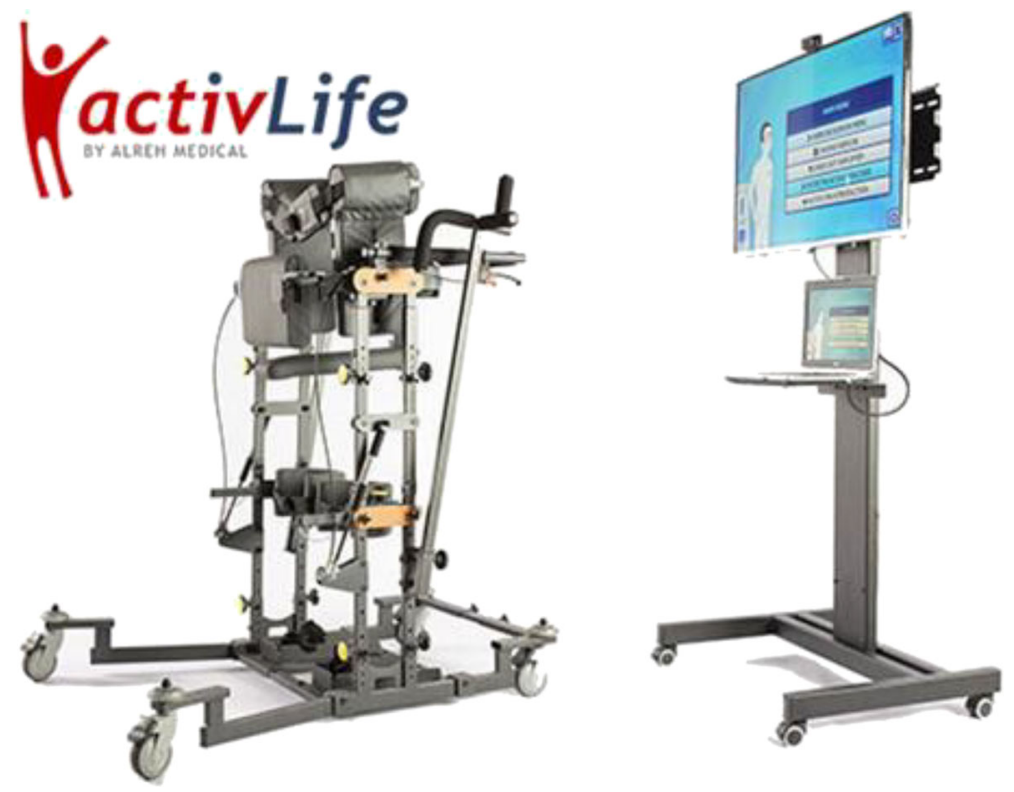

Fig. 11 First version of iStander and ActivLife Gaming Platform (Image: Alreh Medical) 


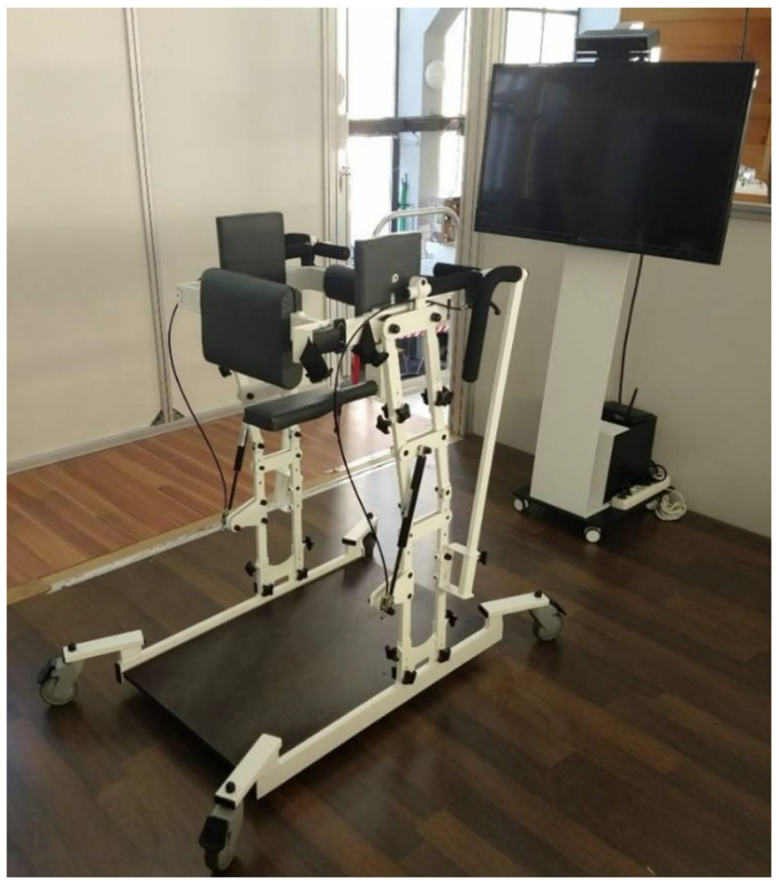

Fig. 12 Upgraded prototypes of $\mathrm{PI}^{2} \mathrm{U}$-iStander and ActivLife Gaming Platform deployed in the laboratory

frequency monitoring mainly for patients sleeping on their abdomens (see Fig. 15) as well as a micro-mobility monitoring, which are both under implementation. Additionally, the project team is currently exploring the possibility of monitoring heart rate by this sensor.

Using image recognition algorithm, the thermal camera targets two major objectives: 1) breath frequency monitoring over the nostrils during sleep on the back, and 2) body

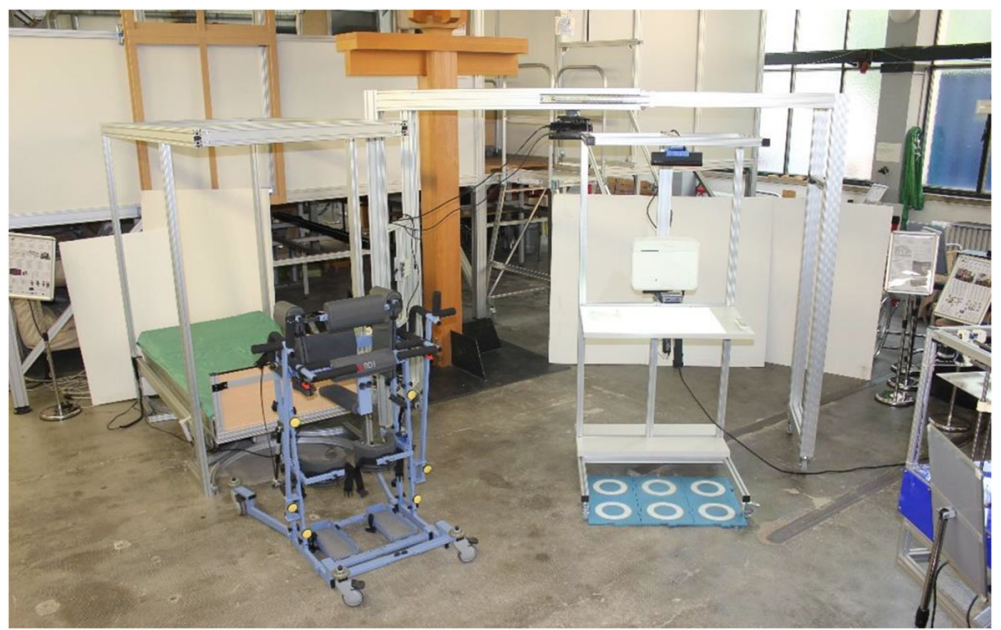

Fig. 13 The prototypes of various $\mathrm{PI}^{2} \mathrm{Us}$ (e.g., $\mathrm{PI}^{2} \mathrm{U}-$ SilverArc, $\mathrm{PI}^{2} \mathrm{U}-\mathrm{Mini} A r c, \mathrm{PI}^{2} \mathrm{U}-\mathrm{SilverBed}$, and $\mathrm{PI}^{2} \mathrm{U}-$ iStander) deployed and tested in the laboratory 


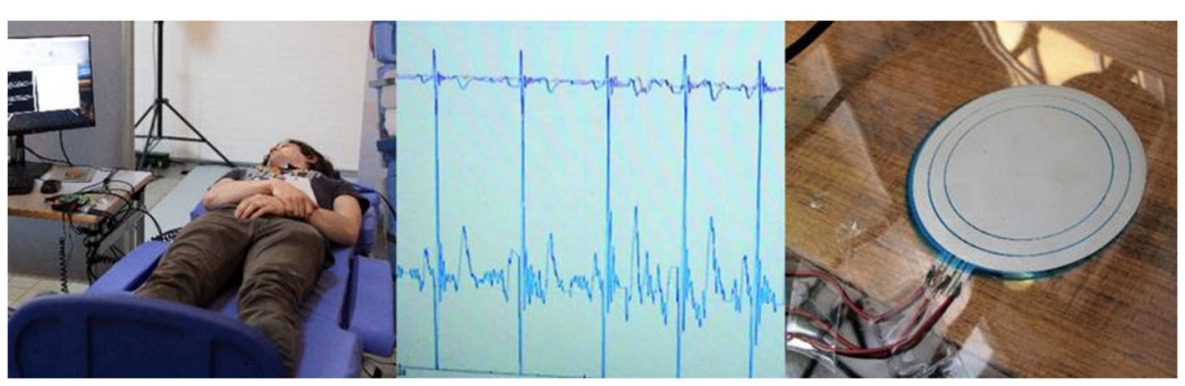

Fig. 14 Testing of the ECG sensors on the $\mathrm{PI}^{2} \mathrm{U}-$ SilverBed

temperature detection/monitoring over the eyes (see Fig. 16). In the first implementation of these modules in laboratory, the results showed the following: breath frequency monitoring is possible and implemented via the nostrils and that the body temperature monitoring is implemented (monitoring the body temperature via the eyes is, naturally, only possible before the patient goes to sleep). There is a small limitation regarding the implemented prototype: due to the resolution of the current thermal camera, it is only possible to monitor these factors in a range of approximately $50 \mathrm{~cm}$ distance from the patient's face. As a result, the thermal camera must either be mounted at the appropriate distance to the face, or the thermal camera must be replaced with a higher quality camera.

The Kinect sensors, integrated into the $\mathrm{PI}^{2} \mathrm{U}-\mathrm{MiniArc}$ and $\mathrm{PI}^{2} \mathrm{U}-\mathrm{SilverArc}$, are used for gesture recognition by considering the hand motions from the user (see Fig. 17). The Kinect was programmed by using the standard libraries from Microsoft. As the Kinect libraries are not compatible with other operating systems, it is therefore essential to continue with Microsoft Windows as the operating system. The control program of the Kinect gesture recognition was programmed using visual studio and was developed separately from the Graphical User Interface (GUI). Furthermore, the software development of the mounted Kinect on the $\mathrm{PI}^{2} \mathrm{U}-$ MiniArc is finalized including the
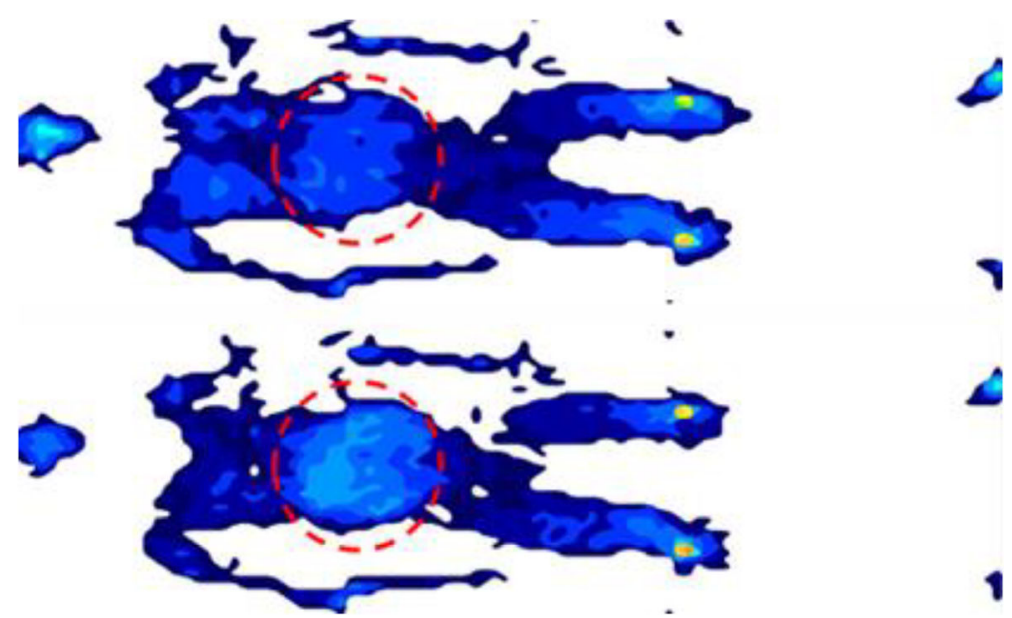

Fig. 15 Pressure change on diaphragm when inhaling and exhaling (generated by the pressure-sensing mattress) 


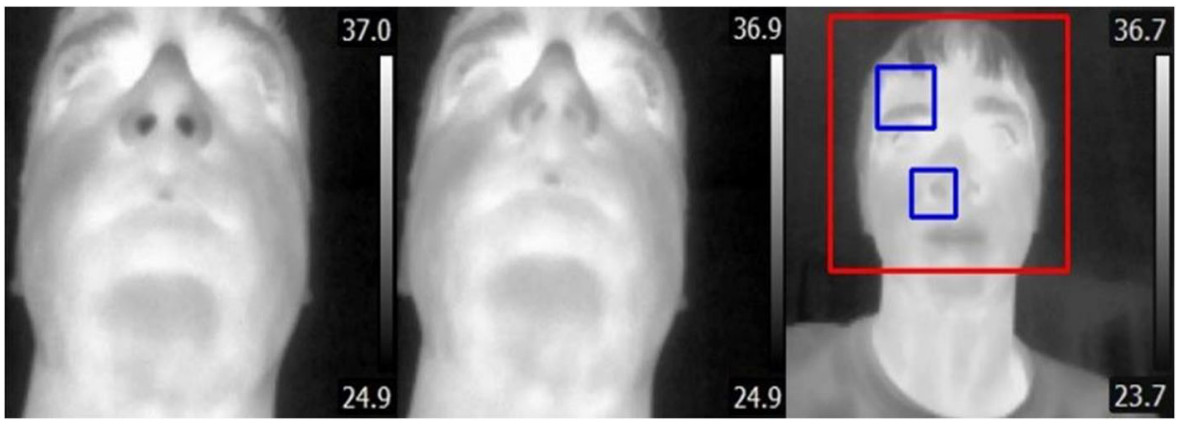

Fig. 16 Respiration rate monitoring and body temperature measurement over the eyes

adjustability for recognizing gestures at two different distances (i.e., standing table surface and sitting table surface).

Furthermore, it was also planned to implement an activity sensing system for the Alreh Medical device (see Fig. 18). This activity sensing system was fused with the current gaming interface of the Alreh Medical device in order to enable lower body interactions with the games. In the first trial, the electromyography (EMG) sensor was implemented and tested. EMG is an electrodiagnostic medicine technique for evaluating and recording the electrical activity produced by the muscles. This was planned to serve as the controller interface for the legs allowing the user to steer a training or rehabilitation game via gestures (e.g., by the Kinect sensor) and leg movements. After the initial implementation and functionality testing in laboratory, the results showed an immense amount of noise when reading the EMG signal both through direct skin contact and over the clothes. This could heavily interfere with the interfacing to the gamification function. As a result, it was decided to consider different approaches for interfacing activity with gamification (e.g., using a touch sensor). Afterwards, such inputs can be used to steer a training or rehabilitation game via foot gestures, which further benefits early detection, monitoring, and activation aspects of the research.

Therefore, this stand-up counting sensor is developed to partially substitute the EMG sensor mentioned above. Designed and implemented as "battery-based" and "plug-and-play", the stand-up counting sensor is mounted on the Alreh Medical device in a specific way, so that the clinical certificate of the device will not be undermined (see Fig. 19). This sensor counts the number of "stand-up" events and transfers this count to a local server via WiFi. In addition, this sensor is implemented with consideration of its exceptionally low power consumption. With the implemented battery, it can run for more than three months without the need for recharging the battery.

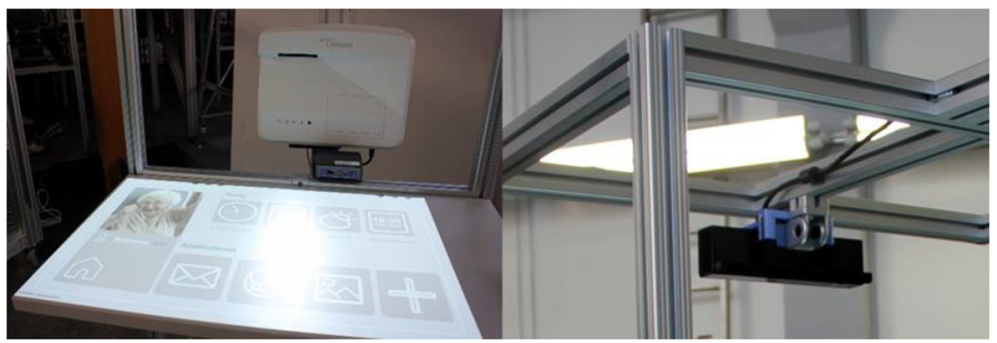

Fig. 17 User interface and Kinect sensor in the $\mathrm{PI}^{2} \mathrm{U}-$ MiniArc 


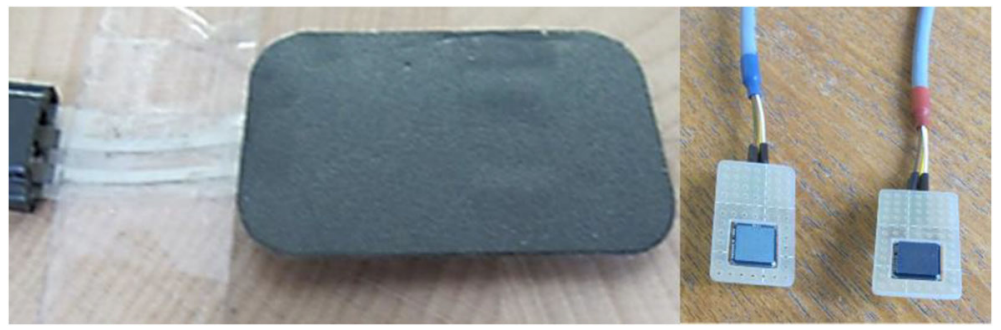

Fig. 18 Activity monitoring sensors used in the $\mathrm{PI}^{2} \mathrm{U}-i$ Stander

Currently, the overall functionality testing of the $\mathrm{PI}^{2} \mathrm{Us}$ in the laboratory was successful. Based on the learnings from the testing, the $\mathrm{PI}^{2} \mathrm{Us}$ will be further revised with more iterations and eventually resemble the proposed furniture design. After the early functionality testing of the prototypes and the first data collection activities, the project team proposed a modularized smart home solution integrating all $\mathrm{PI}^{2} \mathrm{Us}$ and key technologies in four Touchpoints to create a comprehensive interior living and care environment for elderly users. This design shows how the extensive REACH platform can be easily and rapidly tailored to distinct application environments.

\section{Solution for Rapid Implementation}

As mentioned in the previous section, $\mathrm{PI}^{2} \mathrm{Us}$ developed in Touchpoint 2 materialize the project concepts and functionality seamlessly into the different use case settings. Based on the current outcomes from Touchpoint 2 as well as all other Touchpoints, the project team proposed a modularized smart home solution, namely the Total Room Assistive Care Kit (TRACK) concept, which integrates all $\mathrm{PI}^{2} \mathrm{Us}$ and key technologies in $\mathrm{REACH}$ to create a complete interior living and care environment for elderly users. Due to its modularity, selected parts of TRACK can be easily adapted and rapidly deployed in different use case settings in Europe and beyond, which will then help the project to execute a series of testing activities. The proposal of the TRACK concept and its exemplary deployment in one use case setting of the REACH project are reported as follows.

\section{The Application of the TRACK Concept}

By implementing barrier-free design principles, the TRACK concept can be easily adapted and deployed in various living spaces such as community kitchen, activity

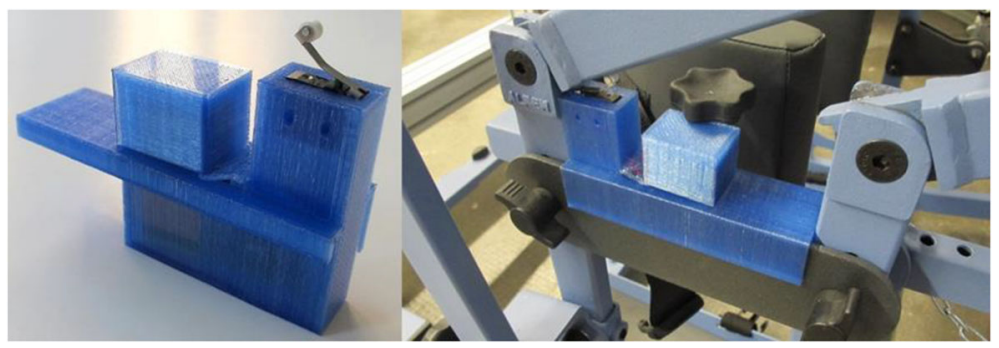

Fig. 19 Stand-up counter embedded in the $\mathrm{PI}^{2} \mathrm{U}-\mathrm{iStander}$ 
room, and patient room, covering most life scenes of the elderly. In these living spaces, rehabilitation devices in Touchpoint 1, smart furniture in Touchpoint 2, socialized nutrition solutions in Touchpoint 3, and gaming/training devices in Touchpoint 4 are seamlessly integrated to create a comprehensive experience of the REACH platform for the users (see Fig. 20).

\section{The Community Kitchen}

The community kitchen serves as a key space for one of the most important daily activities - cooking and eating. It provides an ideal application space for technologies, particularly from Touchpoint 3 (i.e., the "Socializing \& Nutritional Monitoring/

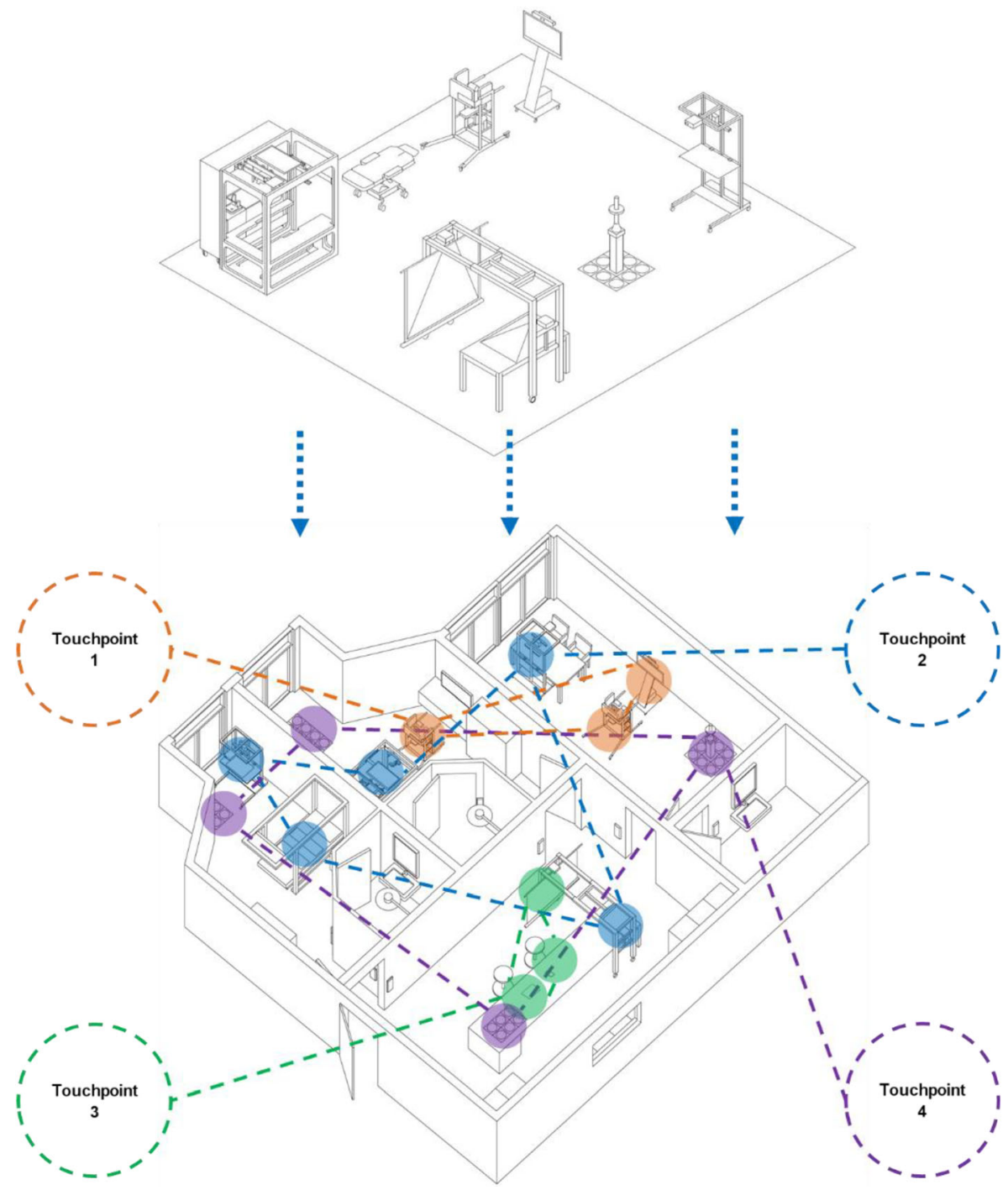

Fig. 20 The Total Room Assistive Care Kit integrated in an exemplary care home 
Intervention" working cluster of the project). The elderly users of the community kitchen can cook and eat together with the help of state-of-the-art technologies. As shown in Fig. 21, the PI²U-SilverArc (or alternatively $\mathrm{PI}^{2} \mathrm{U}-\mathrm{MiniArc}$ ) will project an interactive cooking table allowing the elderly to cook in a smart and interactive way. Furthermore, the elderly in the kitchen are encouraged to use a series of smartphone apps. In addition, healthy and customized food developed by Biozoon (Michail 2016) can be provided to the elderly who use the kitchen. As a result, the seniors are expected to become more socially active and nutritionally healthy due to the usage of the community kitchen.

\section{The Activity Room}

One of the research's main objectives is to encourage the level of exercise of the elderly. Therefore, the activity room provides a flexible space for the elderly to become more physically and mentally active. In this room, the ActivLife gaming platform and the $\mathrm{PI}^{2} \mathrm{U}-\mathrm{iStander}$ training device (developed by Alreh Medical), the $\mathrm{PI}^{2} \mathrm{U}-\mathrm{Mini}$ Arc in both table mode and mobile mode, and the Playware Moto Tiles (Liu et al. 2019) will be implemented to provide the elderly with an active environment to improve their physical and mental health (see Fig. 22).

\section{The Patient Rooms}

In the patient room, the elderly can independently live, exercise, and play cognitive games using the $\mathrm{PI}^{2} \mathrm{U}-$ MiniArc. Meanwhile, when the patient is resting on the $\mathrm{PI}^{2} \mathrm{U}-\mathrm{SilverBed}$, the bed can monitor the user's body temperature and respiration rate by using a thermal camera, the body pressure can be measured using the Pressure Mattress, and ECG data can be monitored by using ECG sensors on the bed (see Fig. 23).

Figure 24 shows a variant of the patient room, in which the $\mathrm{PI}^{2} \mathrm{U}-\mathrm{SilverBed}$ raises to a vertical position, helping the user to stand up easily and transfer into a $\mathrm{PI}^{2} \mathrm{U}-\mathrm{iStander}$ with or without the help of a caregiver. The $\mathrm{PI}^{2} \mathrm{U}-\mathrm{iStander}$ serves as a training device for standing up as well as a mobility device to help the user to move to other areas easily (e.g., bathroom, kitchen, activity room, etc.).

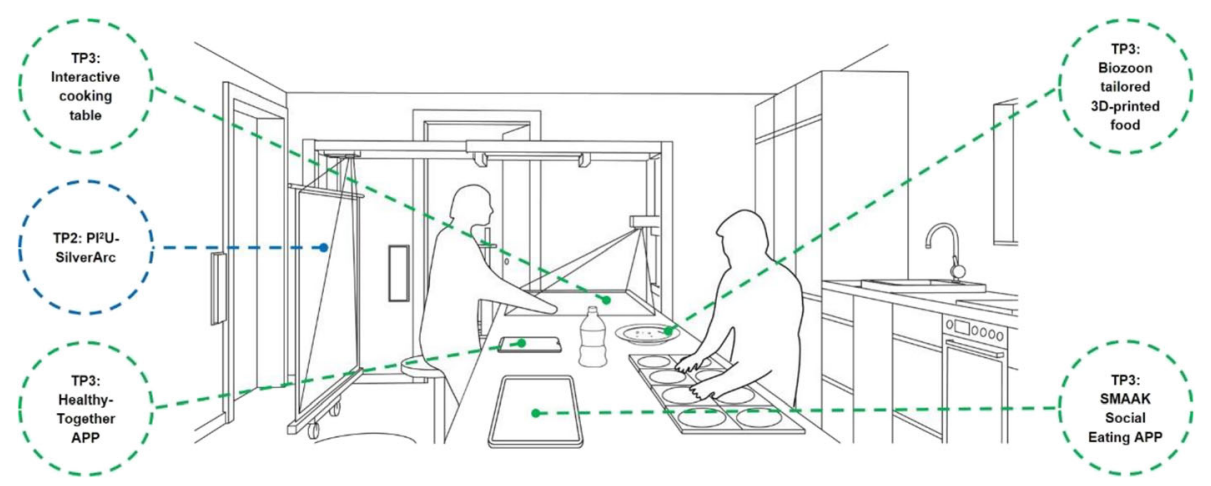

Fig. 21 Simulation of the community kitchen 


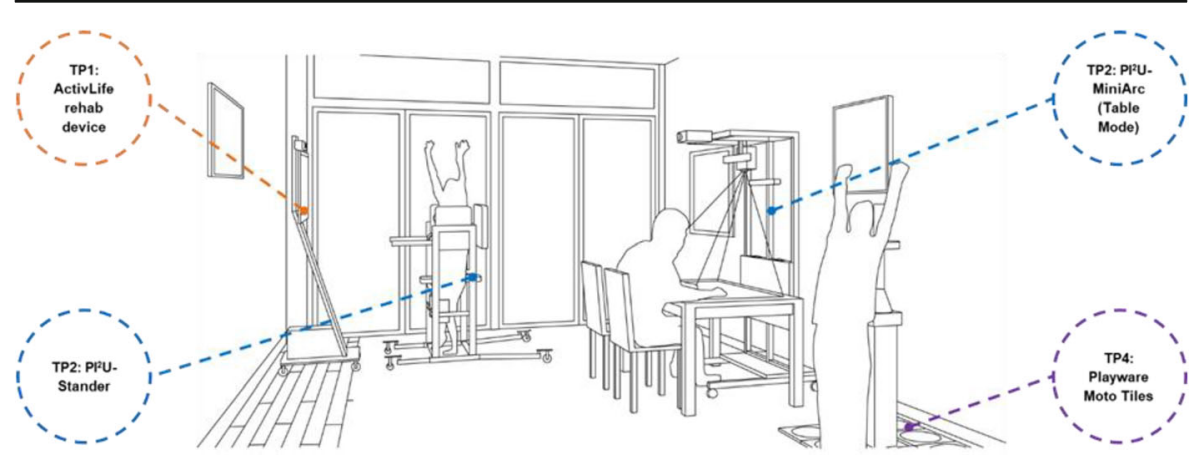

Fig. 22 Simulation of the activity room

\section{Customized Implementation in a Use Case Setting}

In this section, an instance will be presented to demonstrate how the TRACK concept can be applied to rapidly implement the $\mathrm{PI}^{2} \mathrm{Us}$ as customized smart home solutions to existing built environment. The abovementioned TRACK concept played a major role during the exhibition session at the Conference on Active and Healthy Ageing 2019 at Technical University of Denmark (DTU), Lyngby, Denmark, which is one of the use case settings in REACH (Andersen and Ehrari 2019). Technologies developed in REACH were highlighted in the center of the exhibition, along with many other health technology developers, suppliers, and service providers from Denmark and beyond, to showcase their solutions in Oticon Hall at DTU. Based on the TRACK concept, the project team proposed an integrated two-room solution respectively representing community and hospital care environments. The plan was sent to DTU administration for fire safety review and was approved after minor revisions. The exhibition was divided into two main parts: 1) community care environment, and 2) hospital and rehabilitation care environment. The detailed exhibition and demonstration plan is shown below (see Fig. 25), as is a list of various technologies presented in these two contexts (see Table 1).

Due to the application of the TRACK concept, the project team was able to use one day before the exhibition to set up the two care environments and the relevant $\mathrm{PI}^{2} \mathrm{Us}$

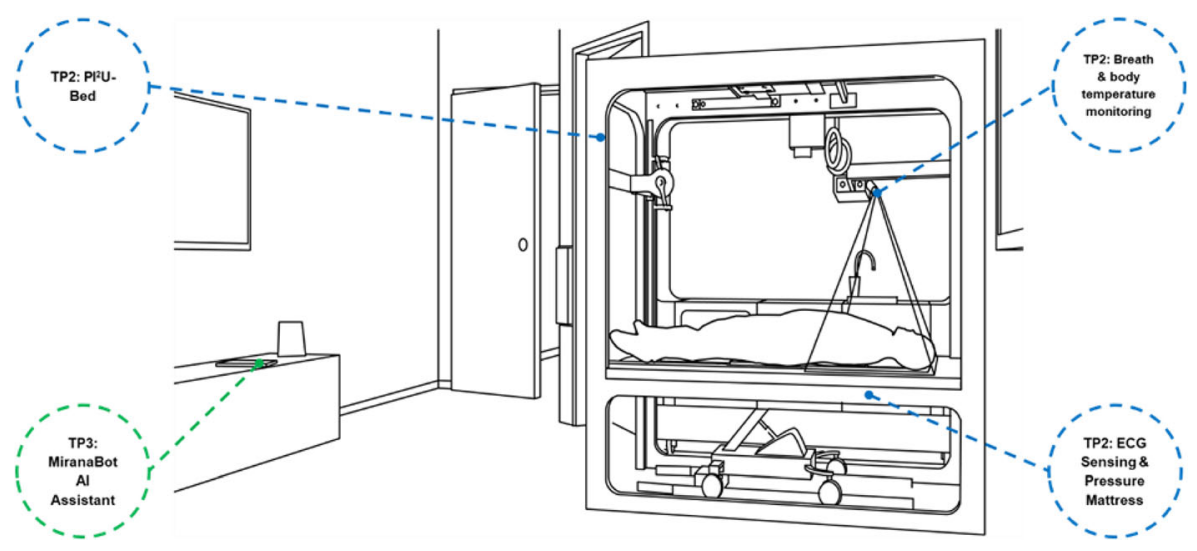

Fig. 23 Simulation of the patient room type A 


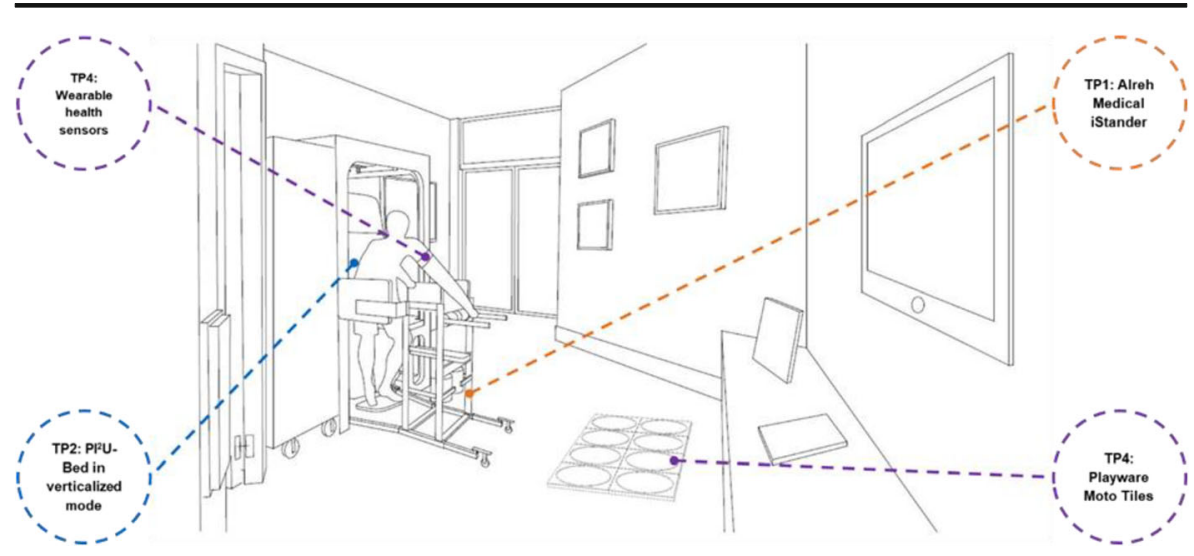

Fig. 24 Simulation of the patient room type B

without any obstacles. On the exhibition day, the listed technologies were demonstrated to visitors (including but not limited to local elderly residents, scholars, EU officials, and entrepreneurs) during the event (see Fig. 26). In general, the exhibition received positive reactions and feedback from the visitors and top researchers which further validated the effectiveness of the proposed concept in this research. The experience gained during the process can be further used to perform similar application in other contexts, as well as to refine and improve the technologies in the next developing phase. Therefore, the exhibition can be considered as one successful application of the customization and materialization of the TRACK concept based on the $\mathrm{PI}^{2} \mathrm{Us}$.

\section{Discussion and Conclusion}

Based on the current research and development results, several insights can be applied to further improve the $\mathrm{PI}^{2} \mathrm{U}$ prototypes, eventually launching them on the market.

First, in the future design iterations of the prototypes, the work priority will be focused on enhancing the user experience of the $\mathrm{PI}^{2} \mathrm{Us}$ together with the elderly people. In order to meet the real needs of the elderly people, design techniques such as

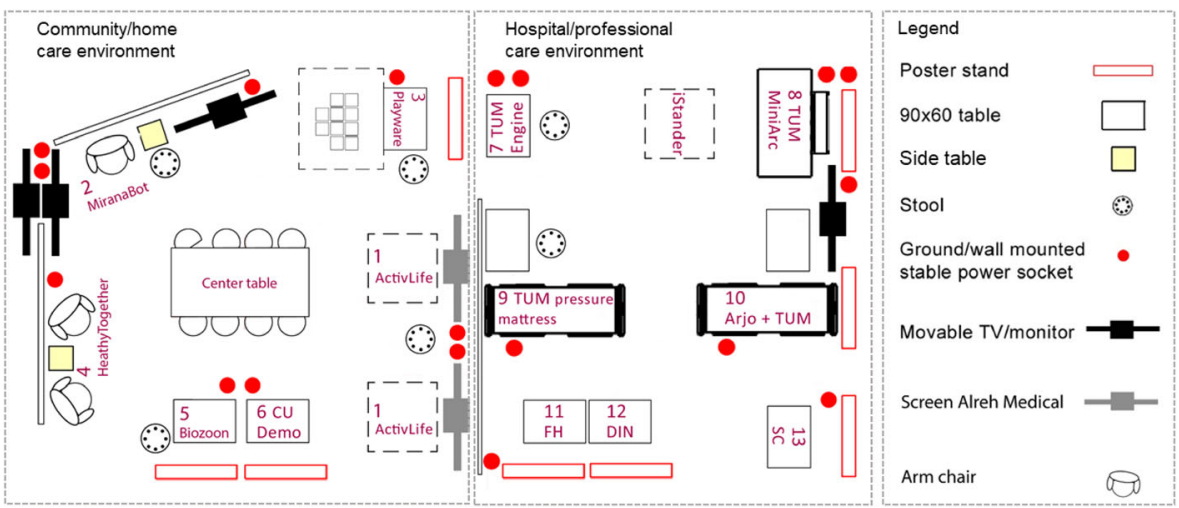

Fig. 25 Proposed REACH exhibition and demonstration plan 
Table 1 List of various technologies presented in the REACH exhibition

\begin{tabular}{|c|c|c|}
\hline Number & Environment & Technology in the REACH exhibition \\
\hline 1 & \multirow{6}{*}{$\begin{array}{l}\text { Community/ home care } \\
\text { environment }\end{array}$} & ActivLife rehabilitation device for seniors, Alreh Medical \\
\hline 2 & & MiranaBot, Geneva University Hospitals \\
\hline 3 & & Moto Tiles, Technical University of Denmark \\
\hline 4 & & HealthyTogether app, Eindhoven University of Technology \\
\hline 5 & & Personalized \& 3D food printer, Biozoon \\
\hline 6 & & Activity trackers showcasing, University of Copenhagen \\
\hline 7 & \multirow[t]{7}{*}{$\begin{array}{l}\text { Hospital/ professional care } \\
\text { environment }\end{array}$} & $\begin{array}{l}\text { CARP Platform in REACH Engine, Technical University of } \\
\text { Munich }\end{array}$ \\
\hline 8 & & $\mathrm{PI}^{2} \mathrm{U}-$ MiniArc, Technical University of Munich \\
\hline 9 & & $\begin{array}{l}\mathrm{PI}^{2} \mathrm{U}-\text { SilverBed (pressure mapping), Technical University of } \\
\text { Munich }\end{array}$ \\
\hline 10 & & $\begin{array}{l}\mathrm{PI}^{2} \mathrm{U}-\text { SilverBed (Sara Combilizer), Technical University of } \\
\quad \text { Munich + Arjo }\end{array}$ \\
\hline 11 & & Activity recognition demonstration, Fraunhofer IAIS \\
\hline 12 & & $\begin{array}{l}\text { Standardization within REACH, Deutsches Institut für } \\
\text { Normung }\end{array}$ \\
\hline 13 & & Medical-grade wearable demonstration, SmartCardia \\
\hline
\end{tabular}

persuasive principles could be applied in this process (Valk et al. 2017). Furthermore, aesthetics of the $\mathrm{PI}^{2} \mathrm{U}$ s needs to be improved regarding the shapes and materials in order to appeal to the elderly users. In parallel, pilot studies involving elderly testing individuals are needed to achieve this goal.

Second, the performance of the devices in terms of responsiveness, endurance, and scalability needs to be further fine-tuned. This step is crucial for ensuring the prototypes to be competitive when entering the market.

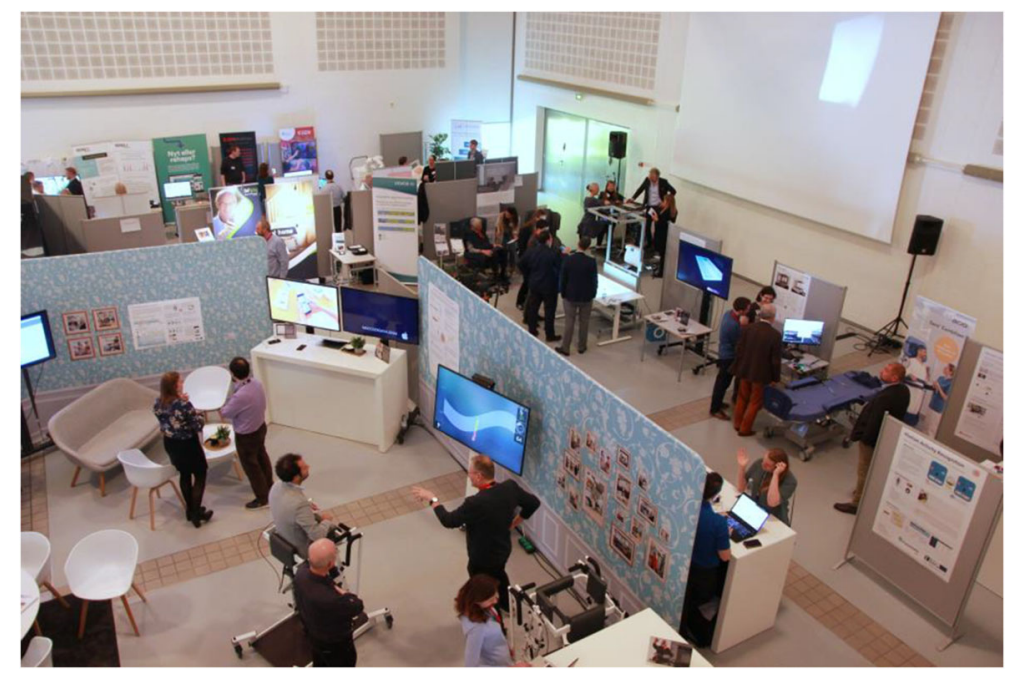

Fig. 26 Aerial view of the exhibition venue 
Third, a variety of cost-benefit analyses (CBA) of solutions using the combinations of $\mathrm{PI}^{2} \mathrm{Us}$ applied in different care environment (e.g., home, hospital, care home) need to be conducted to verify marketability of the proposed solutions as well as to convince potential users and investors. Detailed insights regarding the CBA of the $\mathrm{PI}^{2} \mathrm{Us}$ will be revealed in subsequent research papers.

In conclusion, in this paper, the overall methods of the research are reported. In particular, the development process of the $\mathrm{PI}^{2} \mathrm{Us}$ and their prototypes are described in detail. In conjunction, the main testing, sensing, monitoring, and analysis activities using the $\mathrm{PI}^{2} \mathrm{U}$ prototypes are reported. Based on the functionality validation of the $\mathrm{PI}^{2} \mathrm{Us}$, a comprehensive TRACK concept integrating all relevant $\mathrm{PI}^{2} \mathrm{Us}$ and technologies in the REACH project is proposed, which can later be tailored to various use case settings (e.g., home care, care home, community kitchen, elderly activity center, hospital, etc.). This concept was successfully implemented in the exhibition session at the Conference on Active and Healthy Ageing 2019 in Lyngby, Denmark, and the feedback from the exhibition was utilized to further refine the system. The abovementioned functional testing in laboratory was performed mainly with young healthy individuals. The knowledge and experience generated in this research will serve as a valuable reference for the design and implementation of smart home solutions using smart furniture to promote the elderly's health and quality of life in aging society.

\section{Acknowledgements Open Access funding provided by Projekt DEAL.}

Open Access This article is licensed under a Creative Commons Attribution 4.0 International License, which permits use, sharing, adaptation, distribution and reproduction in any medium or format, as long as you give appropriate credit to the original author(s) and the source, provide a link to the Creative Commons licence, and indicate if changes were made. The images or other third party material in this article are included in the article's Creative Commons licence, unless indicated otherwise in a credit line to the material. If material is not included in the article's Creative Commons licence and your intended use is not permitted by statutory regulation or exceeds the permitted use, you will need to obtain permission directly from the copyright holder. To view a copy of this licence, visit http://creativecommons.org/licenses/by/4.0/.

\section{References}

Andersen, H. B., \& Ehrari, H. (Eds.). (2019). Book of Abstracts from Conference on Active and healthy Ageing 2019. Technical University of Denmark. https://doi.org/10.11581/dtu:00000056

Beetz, M., Stulp, F., Radig, B., Bandouch, J., Blodow, N., Dolha, M., ... Tenorth, M. (2008). The assistive kitchen - A demonstration scenario for cognitive technical systems. Proceedings of the 17th IEEE International Symposium on Robot and Human Interactive Communication (pp. 1-8). https://doi. org/10.1109/ROMAN.2008.4600634.

Bock, T. (2017). REACH: Responsive engagement of the elderly promoting activity and customized healthcare. Gerontechnology, 16(3), 125-128. https://doi.org/10.4017/gt.2017.16.3.001.00.

Cockburn, A. (2008). Using both incremental and iterative development. CrossTalk, 21(5), 27-30 Retrieved from http://static1.1.sqspcdn.com/static/f/702523/9242194/1288741932003/200805-0-Issue.pdf?token= WqH3chsD6mnkMs74vz7JbRc9qY4\%3D.

Erdt, S., Linner, T., Herdener, L., Kreitmair, M., Rieß, J., Roalter, L., ... Moritz, E. F. (2012). Systematic development of a complex personal health assistance system explained by the example of GEWOS activity furniture. Proceedings of the 5th German Ambient Assisted Living Congress. Berlin. Retrieved from https://mediatum.ub.tum.de/doc/1484187/1484187.pdf 
Espinoza, J. (2011). Europe's failing health. The Wall Street Journal. Retrieved from http://www.wsj. com/articles/SB10001424052748704893604576200724221948728

Hsu, C.-H. (2012). Ubiquitous intelligence and computing: Building smart environment in real and cyber space. Journal of Ambient Intelligence and Humanized Computing, 3(2), 83-85. https://doi.org/10.1007 /s12652-011-0074-y.

Hu, R., Kabouteh, A., Pawlitza, K., Güttler, J., Linner, T., \& Bock, T. (2019). Developing personalized intelligent interior units to promote activity and customized healthcare for aging society. Proceedings of 36th International Symposium on Automation and Robotics in Construction (ISARC 2019) (pp. 234-241). Banff, Canada. Retrieved from https://www.iaarc.org/publications/fulltext/ISARC_2019_Paper_60.pdf.

Intille, S. S. (2002). Designing a home of the future. IEEE Pervasive Computing. https://doi.org/10.1109 /MPRV.2002.1012340.

Intille, S. S. (2004). A new research challenge: Persuasive technology to motivate healthy aging. IEEE Transactions on Information Technology in Biomedicine. https://doi.org/10.1109/TITB.2004.835531.

Intille, S. S., Larson, K., Tapia, E. M., Beaudin, J. S., Kaushik, P., Nawyn, J., \& Rockinson, R. (2006). Using a live-in Laboratory for Ubiquitous Computing Research. In K. P. Fishkin, B. Schiele, P. Nixon, \& A. Quigley (Eds.), Pervasive computing (pp. 349-365). Berlin, Heidelberg: Springer Berlin Heidelberg. https://doi.org/10.1007/11748625_22.

Kidd, C. D., Orr, R., Abowd, G. D., Atkeson, C. G., Essa, I. A., MacIntyre, B., ... Newstetter, W. (1999). The aware home: A living Laboratory for Ubiquitous Computing. Proceedings of the International Workshop on Cooperative Buildings (pp. 191-198). https://doi.org/10.1007/10705432_17.

Kozak, D., Burgermeister, S., de Chassey, J. D. B., Naef, A., Maringue, A., \& Dietrich, D. (2017). A functionality, safety and validity study of innovative REACH devices. Gerontechnology, 16(3), 181188. https://doi.org/10.4017/gt.2017.16.3.007.00.

Kurazume, R., Iwashita, Y., Murakami, K., \& Hasegawa, T. (2017). Introduction to the robot town project and 3-D co-operative geometrical modeling using multiple robots. Robotics Research (pp. 505-523). Springer Verlag. https://doi.org/10.1007/978-3-319-29363-9_29, 2017.

Linner, T., Güttler, J., Bock, T., \& Georgoulas, C. (2015). Assistive robotic micro-rooms for independent living. Automation in Construction, 51, 8-22. https://doi.org/10.1016/j.autcon.2014.12.013.

Linner, T., Güttler, J., Georgoulas, C., Zirk, A., Schulze, E., \& Bock, T. (2016). Development and evaluation of an assistive workstation for cloud manufacturing in an aging society. In R. Wichert \& H. Klausing (Eds.), Ambient assisted living: Advanced technologies and societal change (pp. 71-82). Cham: Springer International Publishing. https://doi.org/10.1007/978-3-319-26345-8_7.

Linner, T., Hu, R., Pawlitza, K., \& Güttler, J. (2017). Systems engineering for prevention- oriented, assistive technology situated in a multidisciplinary context. Gerontechnology, 16(3), 129-138. https://doi. org/10.4017/gt.2017.16.3.002.00.

Lipszyc, B., Sail, E., \& Xavier, A. (2012). Long-term care: need, use and expenditure in the EU-27. European Economy - Economic Papers 2008-2015. https://doi.org/10.2765/27485.

Liu, Y.-X., Leggieri, M., \& Lund, H. H. (2019). Playful body and brain test with the Moto tiles. Proceedings of the 2019 International Conference on Artificial Life and Robotics (Vol. 24, pp. 648-651). ALife Robotics Co, Ltd. https://doi.org/10.5954/ICAROB.2019.GS2-6-2.

Manoel, F., Nunes, P., Souza de Jesus, V., Pantoja, C., \& Viterbo, J. (2017). Managing natural resources in a smart bathroom using a ubiquitous multi-agent system, Proceedings of 11th Workshop-School on Agents, Environments and Applications (pp. 101-112). Brazil: São Paulo Retrieved from https://www. researchgate.net/publication/316741200_Managing_Natural_Resources_in_a_Smart_Bathroom_Using_ an_Ubiquitous_Multi-Agent_System.

McPhee, J. S., French, D. P., Jackson, D., Nazroo, J., Pendleton, N., \& Degens, H. (2016). Physical activity in older age: Perspectives for healthy ageing and frailty. Biogerontology. https://doi.org/10.1007/s10522016-9641-0.

McWilliams, D., Atkins, G., Hodson, J., \& Snelson, C. (2017). The Sara Combilizer® as an early mobilisation aid for critically ill patients: A prospective before and after study. Australian Critical Care, 30(4), 189195. https://doi.org/10.1016/j.aucc.2016.09.001.

Michail, N. (2016). Biozoon's 3D printed smooth foods target Europe's elderly. Retrieved June 24, 2019, from https:/www.foodnavigator.com/Article/2016/09/26/Biozoon-s-3D-printed-smooth-foods-target-Europes-elderly

Murakami, K., Hasegawa, T., Kurazume, R., \& Kimuro, Y. (2008). A structured environment with sensor networks for intelligent robots. Proceedings of Sensors, 2008 IEEE (pp. 705-708). https://doi.org/10.1109 /ICSENS.2008.4716539. 
Pehr, S., Zollitsch, D., Güttler, J., \& Bock, T. (2019). Development of a non-contact ECG application unobtrusively embedded into a bed. Proceedings of 2019 IEEE Sensors Applications Symposium (SAS) (pp. 1-6). https://doi.org/10.1109/SAS.2019.8706012.

Pyo, Y., Hasegawa, T., Tsuji, T., Kurazume, R., \& Morooka, K. (2014). Floor sensing system using laser reflectivity for localizing everyday objects and robot. Sensors, 14(4), 7524-7540. https://doi.org/10.3390 /s140407524.

Pyo, Y., Nakashima, K., Kuwahata, S., Kurazume, R., Tsuji, T., Morooka, K., \& Hasegawa, T. (2015). Service robot system with an informationally structured environment. Robotics and Autonomous Systems, 74. https://doi.org/10.1016/j.robot.2015.07.010.

Ren, X., Visser, V., Lu, Y., Brankaert, R., Offermans, S., \& Nagtzaam, H. (2016). FLOW pillow: Exploring sitting experience towards active ageing, in: Proceedings of the 18th international conference on humancomputer interaction with Mobile devices and services adjunct, MobileHCI '16 (pp. 706-713). New York, NY, USA: ACM. https://doi.org/10.1145/2957265.2961841.

Sakamura, K. (1996). The TRON project. Information and Software Technology. https://doi.org/10.1016 /0950-5849(95)01083-1.

Sato, T., Harada, T., \& Mori, T. (2004). Environment-type robot system "RoboticRoom" featured by behavior media, behavior contents, and behavior adaptation. IEEE/ASME Transactions on Mechatronics, 9(3), 529-534. https://doi.org/10.1109/TMECH.2004.834650.

Schäpers, B., Krewer, C., Yasuoka, M., Becker, D., Heller, S., Kaiser, M., Koenig, E., \& Müller, F. (2017). Determining design requirements for active aging: Personas, experience maps, and stakeholders. Gerontechnology, 16, 139-150. https://doi.org/10.4017/gt.2017.16.3.003.00.

Spillman, W. B., Mayer, M., Bennett, J., Gong, J., Meissner, K. E., Davis, B., et al. (2004). A “smart” bed for non-intrusive monitoring of patient physiological factors. Measurement Science and Technology, 15(8). https://doi.org/10.1088/0957-0233/15/8/032.

Stiller, K., \& Phillips, A. (2003). Safety aspects of mobilising acutely ill inpatients. Physiotherapy Theory and Practice. https://doi.org/10.1080/09593980390246751.

Sugano, S., \& Shirai, Y. (2006). Robot design and environment design - Waseda robot-house project. Proceedings of 2006 SICE-ICASE international joint conference. Busan, South Korea. https://doi. org/10.1109/SICE.2006.314981.

United Nations. (2017). World Population Prospects: The 2017 Revision, Key Findings and Advance Tables. Retrieved from https://population.un.org/wpp/Publications/Files/WPP2017_KeyFindings.pdf

Valk, C., Lu, Y., Ren, X., Wintermans, M., Kraaijevanger, I., Steenbakkers, J., \& Visser, V. (2017). Towards personalized persuasive strategies for active ageing. Gerontechnology. https://doi.org/10.4017 /gt.2017.16.3.005.00.

Van der Loos, H. F. M., Ullrich, N., \& Kobayashi, H. (2003). Development of sensate and robotic bed Technologies for Vital Signs Monitoring and Sleep Quality Improvement. Autonomous Robots, 15(1), 67-79. https://doi.org/10.1023/A:1024444917917.

Wichert, R., \& Mand, B. (Eds.). (2017). Ambient Assisted Living - 9. AAL-Kongress, Frankfurt/M, Germany, April 20-21, 2016 (1st ed.). Springer International Publishing. https://doi.org/10.1007/978-3-319-523224.

Williams, B. C., \& Nayak, P. P. (1996). Immobile robots AI in the new millennium. AI Magazine, 17(3), 1635. https://doi.org/10.1609/aimag.v17i3.1229.

Yan, W. X., Fu, Z., Liu, Y. H., Zhao, Y. Z., Zhou, X. Y., Tang, J. H., \& Liu, X. Y. (2007). A novel automatic cooking robot for Chinese dishes. Robotica, 25(4), 445-450. https://doi.org/10.1017 /s0263574706003250.

Publisher's Note Springer Nature remains neutral with regard to jurisdictional claims in published maps and institutional affiliations. 